\title{
VIDEOGAMES E PUBLICIDADE: UMA HISTORICIZAÇÁO SOBRE COMO DIVERTIR E ANUNCIAR
}

\author{
Afonso Ernest Gerhard Markmann ${ }^{1}$
}

\begin{abstract}
Resumo: Os videogames consolidaram-se como forma de entretenimento na década de 1970, quando passaram a ser produzidos em massa e comercializados. Para convencer o público de que ter um console de videogame na sala de casa era algo bom, peças publicitárias persuasivas precisaram ser veiculadas. O presente artigo objetiva mostrar a evolução das publicidades de jogos e videogames ao longo dos anos por meio de uma breve historicização, utilizando uma pesquisa bibliográfica qualitativa.
\end{abstract}

Palavras-chave: Publicidade; Jogos eletrônicos; História dos videogames.

\section{VIDEOGAMES AND ADVERTISING: A HISTORICIZATION ON HOW TO ENTERTAIN AND ADVERTISE}

\begin{abstract}
Videogames have consolidated as a way of entertainment during the 1970's, when they started being mass-produced and commercialized. To persuade the public that having a videogame console in the living room was a good idea, persuasive advertisements had to be run. This article aims to show the evolution of videogames advertisement through the years by the means of a brief historicization through a qualitative bibliographic research.
\end{abstract}

Keywords: Advertising; Electronic games; History of videogames.

\section{Introduçáo}

Durante a década de 70 do século XX, uma nova forma de entretenimento tornou-se extremamente popular: o videogame. Embora jogos eletrônicos tenham existido (ainda que de forma limitada) desde o final da década 1940, a sétima década do século viu o boom dos consoles de videogame. Um console, de acordo com Maahs (2008), é um aparelho que é conectado à televisão e roda jogos eletrônicos para fins de aprendizado e entretenimento. Em 1972, é lançado o Magnavox Odyssey,

1 Bacharel em Comunicação Social com Habilitação em Publicidade e Propaganda pela Universidade do Vale do Taquari - UNIVATES. 
primeiro videogame caseiro. Já em 1977, a Atari traz ao mercado seu Atari 2600. $\mathrm{O}$ console, juntamente com os jogos lançados, popularizaram definitivamente o videogame como forma de entretenimento.

No que diz respeito à forma de vender videogames, há uma relação entre a indústria dos jogos e a publicidade. Por um lado, os jogos podem ser encarados como mídias. Há casos de games produzidos com o único intuito de promover um produto ou marca - os advergames. Mais recentemente, alguns jogos também começaram a incluir anúncios publicitários de terceiros como forma de engajar o jogador com algum produto. Ambos os casos são comuns nas abordagens acadêmicas. Porém, para se promoverem, as marcas de jogos e consoles precisam desenvolver estratégias de comunicaçáo. Este aspecto tem sido pouco abordado. Houve mudanças significativas na forma de anunciar ao longo desses 40 anos de "popularização" do videogame?

Assim sendo, o artigo objetiva historicizar as formas de anunciar consoles e jogos, também tratando a evolução dos videogames como forma de contextualizar a publicidade nesta área. A historicização será feita através de uma revisão bibliográfica de artigos e monografias que abordam videogames e comunicação, assim como de livros destas áreas. Um exemplo é o autor Steven L. Kent, que em 2001 lançou a obra The Ultimate History of Video Games.

A primeira seção do artigo apresentará a história dos videogames de forma resumida, desde o surgimento dos primeiros jogos eletrônicos até os dias atuais. A segunda parte buscará acompanhar esta evolução através da publicidade de consoles e jogos, expondo mudanças e constantes ao longo dos anos.

\section{Uma breve história dos videogames}

De acordo com Batista et al (2007), o consenso é de que o primeiro videogame tenha surgido em 1958, criado por Willy Higinbotham. Tennis for Two podia ser jogado por meio de um osciloscópio. Em 1961, pesquisadores do MIT desenvolveram Space War!, jogo que era executado em um computador DEC PDP 1. Em 1971, surge o primeiro fliperama, também chamado de arcade. Tratase de uma máquina pública que necessita de fichas ou moedas para ser utilizada. Computer Space, o primeiro fliperama, não vendeu muito bem devido ao seu alto custo.

No ano de 1972, é lançado o Odyssey 100, primeiro console da história. Conforme Kent (2001), no ano seguinte, Nolan Bushnell e Ted Dabney, criadores do Computer Space, deram início à Atari, empresa que se especializaria em desenvolver jogos de fliperama. O primeiro produto lançado pela nova empresa foi Pong, game que representava uma partida de pingue-pongue e que logo mostrou fazer bastante sucesso. A grande virada da indústria aconteceu em 1977, quando a Atari lançou seu primeiro console: o Atari 2600. A partir deste momento, várias empresas apostaram no lançamento de jogos para o sistema, fazendo o mundo conhecer títulos como Space Invaders e Pac-Man, como lista Maahs (2008). 
A prosperidade da indústria sofreu uma queda em 1982. No Natal daquele ano, E.T. the Extraterrestrial chegava às lojas. Boyd (2016) diz que o jogo teve um tempo de desenvolvimento de apenas cinco semanas, deixando visível a má qualidade do produto final. A maioria das cópias compradas foi devolvida, o que somado à grande quantidade de jogos repetitivos disponíveis no mercado, gerou o crash no mercado dos videogames entre 1983 e 1984 . O alto número de aparelhos presentes no mercado também teve seu papel no crash do início da década de 1980

A diversidade de aparelhos produzidos, alguns com baixa qualidade, inundaram um mercado um tanto saturado, que já contava com microcomputadores pessoais para tarefas da família (planilhas, organização, educação e jogos) e cujo valor não era muito diferente dos simples videogames que se tornavam obsoletos. (MAAHS, 2008, p. 17)

A salvação dos consoles se deu através da Nintendo, empresa japonesa que, em 1983, lançou o Nintendo Famicom, levando-o em 1985 aos Estados Unidos com o nome Nintendo Entertainment System - NES (KENT, 2001). O console trouxe novos ares à indústria, mostrando que ainda havia público para o mercado de videogames e jogos eletrônicos.

O NES foi um sucesso de vendas ao redor do mundo. Kent (2001) lista The Legend ofZelda, Donkey Kong e Super Mario Bros. como alguns dos jogos catalisadores da popularidade do console. Isso permitiu à Nintendo lançar mais consoles, jogos e até uma revista ao longo dos anos seguintes. Ainda em 1986, é lançado pela Sega o Master System. À época, o Master System não representou grande perigo à Nintendo, mas anos depois a Sega se tornaria a principal concorrente da empresa responsável por Super Mario Bros. (BATISTA et al, 2007).

Super Nintendo, Sega Genesis (ou Mega Drive), Nintendo 64 e Sega Saturn são alguns dos consoles lançados durante a década de 1990. Em 1994, a Sony entrou no mercado lançando seu próprio videogame, o PlayStation. Em 2001, a Microsoft fez o mesmo com o Xbox. Em 1998, a Sega traz às lojas o Dreamcast, aquele que seria o último console da empresa (ela limita-se a lançar apenas jogos para outras plataformas desde entáo). Conforme listado na Wikipédia, desde 2012 os consoles de videogame encontram-se em sua oitava geração. Trata-se do Playstation 4 (Sony), Xbox One (Microsoft) e Wii U (Nintendo). Em 2017, a Nintendo lançou o Switch, que foi classificado como um híbrido de console de mesa e portátil.

\section{A publicidade e a indústria do videogame}

Quando o popular jogo Pong chegou ao Magnavox Odyssey em 1974, várias tentativas foram feitas para vender o console com o jogo em lojas de brinquedos e de eletrônicos (KENT, 2001). Como tais estabelecimentos não estavam convencidos de que vender o console seria lucrável, a próxima opção eram as lojas de departamentos. Segundo o autor, os departamentos de brinquedos e eletrônicos da rede Sears também recusaram a ideia de comercializar Pong. Entretanto, o departamento de produtos esportivos da Sears já anunciava o Odyssey em seu catálogo, e logo foi convencido a anunciar a versão do console com Pong incluso. Isto foi facilitado pelo 
fato de que o jogo simulava uma partida de pingue-pongue, o que poderia atrair quem comprasse produtos similares para salas de recreação.

No início da indústria de consoles de videogame caseiros, a publicidade mostrava o produto de forma quase educativa, de maneira a apresentar a novidade aos consumidores. Do mesmo modo, os anúncios focavam na figura do jogador, pouco mostrando os jogos em si

Quando os videogames chegaram pela primeira vez aos lares e sempre que um novo console é apresentado, as publicidades gráfica e televisiva frequentemente mostraram jogadores em vez de jogos. Ao fazer isso, estes anúncios serviram como forma de treinar o público a usar estes aparelhos, assim como mostrar quem é visto como o público-alvo do produto. (YOUNG, 2007, p. 235. Tradução livre minha). ${ }^{2}$

Além de educar o consumidor, esta forma de anunciar também explicitava a quem era destinado o produto em questão, no caso, o videogame. Em vários comerciais, é possível ver pessoas de diferentes faixas etárias, tanto homens quanto mulheres, interagindo com o produto. Como explicado por Young (2007), tal fenômeno (ou mudança) na publicidade de games acontece toda vez que um novo console é lançado.

Quanto à comercialização e à forma de anunciar o NES, Kent (2001) relata que a maioria dos varejistas ainda não estava muito interessada em videogames, não querendo desperdiçar o espaço das lojas com consoles. Por este motivo, em 1985 a Nintendo abordou os vendedores com cuidado, usando o termo "sistema de entretenimento", e não "videogame", ao se referir ao NES. Desta forma, Gail Tilden, responsável pela publicidade da Nintendo, contratou os serviços de uma agência publicitária para dar o tom da campanha norte americana do NES. Somado a isso estavam os esforços de Minoru Arakawa, presidente da Nintendo of America. Arakawa garantiu aos varejistas uma oferta livre de riscos: a Nintendo compraria de volta qualquer produto não vendido pelas lojas. Estas apenas cederiam o espaço, e a Nintendo se encarregaria de fazer o merchandising. Segundo Silva (1990 apud Memória, 2010), "merchandising significa uma atividade mercadológica utilizável para fazer fluir os bens de consumo através dos canais de marketing”. Era uma estratégia atraente aos varejistas e perigosa à Nintendo, mas que no final funcionou.

Em 1985, o personagem Mario se tornou extremamente popular no Japão com o lançamento do jogo Super Mario Bros. O Famicom passou a ser vendido com uma cópia do jogo, e o mesmo passou a ser feito com o NES quando Super Mario Bros. chegou à América do Norte, em 1986 (KENT, 2001). A sequência Super Mario Bros. 2 foi lançada em 1986 no Japão, chegando aos Estados Unidos dois anos depois. Maahs (2008) explica que um terceiro título, Super Mario Bros.

2 When videogames were first brought into the home and whenever a new form of videogame hardware is introduced the print and television advertisements have frequently featured players rather than the games. In doing so, these ads have served as a way of training the public on how to use these devices as well as illustrating who is seen as the product's intended user. 
3, foi lançado no Japão em 1988, com lançamento americano previsto para 1989. Entretanto, a falta de matéria prima para a produção dos cartuchos impossibilitou o cumprimento da data. Para contornar o problema, a Nintendo fez uso de uma interessante jogada publicitária.

Em 1989 chegou aos cinemas The Wizard (O Gênio do Videogame, no Brasil). Trata-se de um filme usado para divulgar os produtos e a marca Nintendo, além de mostrar Super Mario Bros. 3 pela primeira vez ao público norte americano (MAAHS, 2008). O jogo em si é visto no ato final de filme, fazendo a grande revelação do novo título aos espectadores.

Assim como em outros anúncios da época descritos anteriormente por Young (2007), The Wizard tem seu lado educativo. A película, de acordo com Maahs (2008), demonstra e explica o produto (jogo), e também apresenta os personagens descobrindo segredos de Super Mario Bros. 3. Maahs (2008) também afirma que o sucesso de The Wizard contribuiu para que o cartucho de Super Mario Bros. 3 vendesse muito bem em solo americano.

No ano de 1994, a Sony lança seu primeiro console, o PlayStation. Antes do videogame chegar às prateleiras, a empresa divulgou alguns vídeos promocionais misteriosos. Após rápidos cortes entre imagens fora de contexto e instantes de gameplay, os VTs terminavam com a mensagem "[E]NOS Lives". Oravasaari (2012) explica que o "E" representa a palavra ready ("pronto"), e "NOS" significa ninth of September ("nove de setembro"), data de lançamento do PlayStation.

Seguindo o lançamento do console da Sony e sua campanha, o público em geral começou a perceber o lado maduro e a diversidade dos jogadores. Com isso, foi lançado o VT Double Life, que apresentava pessoas de distintas classes, gêneros e estilos de vida demonstrando sua paixão aos games e o significado de ser um gamer. O slogan "Do Not Underestimate the Power of PlayStation" ("Não subestime o Poder do PlayStation", em tradução livre) aparece ao final do vídeo, e também viria a ser utilizado em várias peças publicitárias gráficas (ORAVASAARI, 2012). Chess (2010) concorda que as campanhas publicitárias de videogames passaram recentemente a reconhecer a diversidade do público-alvo, em especial mulheres.

Entretanto, conforme o mercado de videogames avança pelo século XXI, também surgem açôes publicitárias de gosto duvidoso. Klepek (2015) lembra da ocasiáo em que a Sony promoveu, em 2007, uma festa para divulgar o jogo God of War II, do PlayStation 2. O game tem como temática a mitologia grega, e além de trazer figuras características, mostra excessos de sangue, violência e nudez. A festa promovida pela empresa trazia os mesmos elementos: além de mulheres seminuas circulando pelo local distribuindo frutas, havia a carcaça de uma cabra sacrificada. Fotos do evento foram publicadas em uma ediçáo da revista PlayStation do Reino Unido, mas 80 mil exemplares foram retirados de circulação após uma matéria publicada pelo tabloide Daily Mail ter criticado a ação da Sony (KLEPEK, 2015). 


\section{Consideraçóes finais}

Os videogames passaram por diversas e significativas mudanças ao longo dos anos, e as formas de anunciar consoles e jogos tiveram que acompanhar essa trajetória. Os primórdios da indústria provaram ser difíceis; tratando-se de uma inovação, era difícil convencer o público a aceitar a nova forma de entretenimento baseada em conectar um aparelho à TV e interagir através de um controle. A publicidade se mostrou uma valiosa ferramenta para persuadir consumidores a apostarem neste novo mercado.

Como foi possível perceber, os primeiros anúncios publicitários de consoles serviam para educar o público em relaçáo ao produto. Era algo necessário para as pessoas entenderem do que se tratava um videogame e a quem ele era destinado. Quebrada essa barreira de estranheza, as marcas passaram a apostar em estratégias mais ambiciosas, levando até jogos e personagens aos cinemas.

No final do século XX, videogames pararam de ser vistos como algo exclusivamente infantil ou antissocial, e a publicidade teve seu papel nesta mudança. Tais rótulos por si já são injustos, sendo que os videogames nunca foram anunciados com o intuito de atingir um público-alvo táo pequeno. Mesmo assim, veicular anúncios que mostram facetas diferentes das mencionadas contribui para que pessoas com receio de serem rotuladas percam o medo e experimentem jogos eletrônicos. Neste quesito, a publicidade vem evoluindo de forma coerente, frequentemente surpreendendo o público em geral com comerciais e outras peças.

Vale frisar que o presente artigo objetiva historicizar a evolução da indústria dos videogames e a sua publicidade. Apenas uma pequena parte desta grandiosa história foi contada aqui, e um estudo mais detalhado necessita ser feito a fim de obter-se um entendimento maior da intrínseca relação videogame-publicidade. $\mathrm{Na}$ sétima e oitava geração de consoles, por exemplo, o videogame está constantemente conectado à internet. Isto abriu um grande leque de possibilidades para anunciar jogos, algo impensável nos primórdios da indústria.

Conforme avançamos no tempo, publicidade, videogames, costumes e ideias mudam. A diversão, entretanto, é uma constante.

\section{Referências}

BATISTA, Mônica et al. Um estudo sobre a história dos jogos eletrônicos. 2007. Revista Eletrônica da Faculdade Metodista Granbery; n. 3 (2007). Disponível em <http:// re.granbery.edu.br/artigos/MjQ4.pdf>. Acesso em 16 mai. 2018.

BOYD, Andy. The Videogame Crash of 1983. In: University of Houston. Disponível em <https://www.uh.edu/engines/epi3038.htm>. Acesso em 03 de jun. 2018.

CHESS, Shira. A 36-24-36 Cerebrum: Productivity, Gender, and Video Game Advertising. Critical Studies in Media Communication; vol. 28, n. 3. Disponível em <https://www.tandfonline.com/doi/ 
full/10.1080/15295036.2010.515234?scroll=top\&needAccess=true>. Acesso em 17 jun. 2018.

KENT, Steven L. The Ultimate History of Video Games: From Pong to Pokémon and Beyond...the Story Behind the Craze That Touched Our Lives and Changed the World. Three Rivers Press, 2001.

KLEPEK, Patrick. That Time Sony Threw A God of War Party With A Dead Goat. In: Kotaku. Disponível em: <https://kotaku.com/that-time-sony-threw-a-god-of-war-partywith-a-dead-goa-1734350134>. Acesso em 23 jun. 2018.

LIST OF HOME VIDEO GAME CONSOLES. In: Wikipedia. Disponível em <https:// en.wikipedia.org/wiki/List_of_home_video_game_consoles>. Acesso em 16 mai. 2018.

MAAHS, Luciane. A publicidade no universo dos videogames: Mario Bros - um fenômeno de vendas. 2008. 75 f. Monografia (Projeto Experimental em Propaganda I) Faculdade de Biblioteconomia e Comunicação, Universidade Federal do Rio Grande do Sul, Porto Alegre, RS, 2008.

MEMÓRIA, Paula Roberta Fernanda. O merchandising em ponto-de-venda como ferramenta de estratégia para vendas no varejo. Revista Eletrônica da Faculdade Metodista Granbery; n. 8 (2010). Disponível em <http://re.granbery.edu.br/artigos/ MzY1>. Acesso em 10 jun. 2018.

THE HISTORY OF PLAYSTATION ADS: PSONE. Oravasaari, Dan. In: PlayStation Lifestyle. Disponível em <http://www.playstationlifestyle.net/2012/03/01/the-history-ofplaystation-ads-psone/>. Acesso em 15 jun. 2018.

YOUNG, Bryan-Mitchell. The Disappearance and Reappearance and Disappearance of the Player in Videogame Advertising. 2007. 8 f. Artigo (Conferência DiGRA 2007) Universidade de Indiana, 2007. 